EXTENDED REPORT

\title{
Soluble TRAIL concentrations are raised in patients with systemic lupus erythematosus
}

\author{
M N Lub-de Hooge, E G E de Vries, S de Jong, M Bïl
}

See end of article for authors' affiliations

.....................

\section{Correspondence to:}

Dr M Biil, Department of

Clinical Immunology

University Hospital

Groningen, PO Box 30.

001,9700 RB Groningen,

Netherlands; m.bij|@int.

azg.nl

Accepted

21 November 2004

Published Online First

25 November 2004
Background: Increased apoptosis may induce autoimmune conditions. Apoptosis is induced by binding of death receptor ligands, members of the tumour necrosis factor (TNF) superfamily, to their cognate receptors. The Fas-Fas ligand pathway has been studied extensively in relation to systemic lupus erythematosus (SLE). However, other death pathways are also considered important. TNF related apoptosis inducing ligand (TRAIL), another ligand of the TNF superfamily, induces apoptosis in sensitive cells.

Objective: To assess soluble (s) TRAIL concentrations in sera of SLE patients.

Methods: 40 SLE patients were studied (20 with active and 20 with inactive disease). Serum sTRAIL concentrations were measured by a solid phase sandwich enzyme linked immunosorbent assay. Levels in SLE patients were compared with those in patients with rheumatoid arthritis $(n=20)$, Wegener's granulomatosis $(n=20)$, and healthy controls $(n=20)$.

Results: Mean (SEM) serum sTRAIL concentration in SLE patients $(936.0$ (108.2) pg/ml) was higher than in healthy controls $(509.4(33.8) \mathrm{pg} / \mathrm{ml} ; \mathrm{p}<0.01)$ or in disease control patients with rheumatoid arthritis (443.8 (36.1) pg/ml, $\mathrm{p}<0.001$ ) or Wegener's granulomatosis (357.1 (32.2) pg/ml; $\mathrm{p}<0.001$ ). The mean serum sTRAIL concentration was $1010.2(168.0) \mathrm{pg} / \mathrm{ml}$ for patients with inactive disease and 861.8 (138.7) $\mathrm{pg} / \mathrm{ml}$ for those with active disease. sTRAIL values were not correlated with specific manifestations of the disease, such as leucopenia or lymphopenia, or with SLE disease activity index.

Conclusions: Serum sTRAIL concentrations are increased SLE patients. This seems to be disease specific and could indicate a role for TRAIL in SLE pathophysiology.
$\mathrm{S}$ ystemic lupus erythematosus (SLE) is an autoimmune disease with a broad spectrum of clinical and immunological abnormalities. The presence of autoantibodies, especially those directed to double stranded DNA, is characteristic of the disease. SLE may affect different organ systems, including the skin, joints, central and peripheral nervous system, kidneys, and liver. The aetiology of the disease remains unknown. There is, however, increasing evidence that the presence and accumulation of apoptotic cells play a role in autoimmunity. ${ }^{1}$

Apoptosis (programmed cell death) is an active physiological process that leads to the ordered destruction of cells without the release of intracellular contents into the extracellular environment (which would cause an inflammatory reaction and tissue damage). It is fundamental to maturation and homeostasis of the immune system. Apoptosis can be induced passively, through lack of essential survival signals, or actively, through ligand induced trimerisation of specific death receptors of the tumour necrosis factor (TNF) receptor family, such as Fas, the TNF receptor, or the TNF related apoptosis inducing ligand (TRAIL) receptor.

The Fas mediated apoptosis pathway has been studied extensively in relation to SLE and other autoimmune diseases (reviewed by Nagata ${ }^{2}$ and Famularo et $a l^{3}$ ). Fas, also known as APO-1 or CD95, is an apoptosis signalling receptor on the cell surface. It is expressed on subpopulations of peripheral blood lymphocytes, predominantly memory $\mathrm{T}$ cells, and upon activation it is strongly upregulated on both $\mathrm{T}$ and B lymphocytes. It can also be found in serum as a soluble form, lacking its transmembrane region. Soluble Fas (sFas) is functionally active when injected into female CDl mice, resulting in autoimmune features and lymphadenopathy ${ }^{4}$; in that study it was shown that sFas blocked Fas induced apoptosis. Serum sFas and soluble Fas ligand ( $\mathrm{sFasL}$ ) levels are raised in patients with SLE. ${ }^{5}$ However, in contrast to the data obtained from animal models, in SLE patients the induction of Fas induced apoptosis in peripheral blood lymphocytes is increased rather than decreased.

TRAIL (APO-2 ligand) is a transmembrane (type II) glycoprotein which also belongs to the TNF superfamily. ${ }^{6}$ The extracellular domain of TRAIL is homologous to that of other family members and shows a homotrimeric subunit structure. Like TNF and FasL, TRAIL also exists physiologically in a biologically active soluble homotrimeric form. TRAIL triggers apoptosis through interaction with the death receptors DR4 (TRAIL-R1) and DR5 (TRAIL-R2) (reviewed by LeBlanc and Ashkenazi ${ }^{7}$ ).

There are several indications that TRAIL could be involved in the pathophysiology of autoimmune diseases in general and SLE in particular. In patients with multiple sclerosis, FasL and TRAIL are upregulated in peripheral blood mononuclear cells. ${ }^{8}$ In patients with Sjögren's syndrome TRAIL-RI and TRAIL-R2 are strongly expressed on the ductal epithelial cells in the salivary glands. ${ }^{9}$ Recently Kaplan et al reported that increased expression of TRAIL and FasL found on activated $\mathrm{T}$ cells contributes to increased monocyte apoptosis in patients with SLE. ${ }^{10}$ Furthermore increased mRNA for TRAIL and its decoy receptors (TRAIL-R3 and TRAIL-R4) was found in peripheral blood mononuclear cells from SLE patients. ${ }^{11}$

Abbreviations: ACR, American College of Rheumatology; ELISA, enzyme linked immunosorbent assay; FasL, Fas ligand; IFN, interferon; $\mathrm{OD}$, optical density; PBMC, peripheral blood mononuclear cells; SLE, systemic lupus erythematosus; SLEDAI, SLE disease activity index; TNF, fumour necrosis factor; TRAIL, TNF related apoptosis inducing ligand 
The Fas/FasL system in SLE is functionally intact, but upregulation of these membrane molecules does not seem to explain the increased numbers of apoptotic cells found in the peripheral blood of these patients. ${ }^{12}$ We hypothesise that secreted sTRAIL might also be important in the induction of apoptosis in SLE. Currently there are no data on serum sTRAIL concentrations in SLE patients compared with healthy volunteers and disease controls with rheumatoid arthritis or Wegener's granulomatosis. Matsuyama et al recently showed that serum TRAIL concentrations were negatively correlated with neutrophil counts in SLE patients, suggesting that there is sTRAIL induced apoptosis of neutrophils in SLE. ${ }^{13}$ It is, however, unknown whether increased sTRAIL levels in SLE patients are disease specific and dependent on disease activity.

\section{METHODS \\ Patients}

Clinical data and serum samples for all patients with SLE who are referred to the University Hospital Groningen are stored consecutively in a computerised database. The patients for our study were selected from this database. They were eligible for the study if they fulfilled at least four American College of Rheumatology (ACR) criteria for SLE. ${ }^{14}$ We included 20 consecutive SLE patients with inactive disease, defined as the persistent absence of disease activity (SLE disease activity index (SLEDAI) $\leqslant 4$ ) over at least a four month period with no immunomodulating drug treatment or on a constant dose of an immunomodulating agent. The SLEDAI score was calculated for each patient. ${ }^{15}$ In addition, the effect of disease activity in 20 SLE patients with active disease was studied. Patients with active disease had to fulfil previously defined criteria. ${ }^{16}$ As disease controls we included consecutive patients with rheumatoid arthritis $(n=20 ; 5$ male, 15 female; mean (SD) age, 51.5 (12.1) years) and Wegener's granulomatosis $(\mathrm{n}=20 ; 13$ male, 7 female; 51.2 (21.1) years), all fulfilling respective ACR criteria. ${ }^{17}$. Healthy volunteers $(\mathrm{n}=20$; 9 male, 11 female; 37.4 (11.5) years) served as controls.

\section{Laboratory assessments}

For SLE patients laboratory assessments included serum levels of C3, C4, and C reactive protein, and leucocyte, neutrophil, monocyte, and lymphocyte counts. Antibodies to dsDNA were detected by Farr assay.

\section{Enzyme linked immunosorbent assay for TRAIL}

Serum samples were stored at $-20^{\circ} \mathrm{C}$ until assayed for sTRAIL concentrations. Serum levels of sTRAIL were determined by a validated sandwich solid phase enzyme linked immunosorbent assay (ELISA) (Diaclone, Besançon, France). A monoclonal antibody specific for sTRAIL was coated onto the wells of the microtitre strips. An aliquot of $100 \mu \mathrm{l}$ of undiluted serum was pipetted in duplicate into the wells. During the first incubation, the sTRAIL antigen and a biotinylated monoclonal antibody specific for sTRAIL were simultaneously incubated for three hours at room temperature $\left(18-25^{\circ} \mathrm{C}\right)$. After washing, the enzyme streptavidin-poly horseradish peroxidase was added. After incubation for 30 minutes and washing to remove unbound enzyme, a substrate solution was added to the bound enzyme to induce a coloured reaction product. The optical density (OD), reflecting the intensity of the product, was measured in a spectrophotometer using $450 \mathrm{~nm}$ as the primary wavelength and $650 \mathrm{~nm}$ as the reference wavelength. Linear calibration curves were made using standard TRAIL (0-3000 pg/ml), provided with the kit. The amount of sTRAIL in the serum samples was determined by extrapolating OD values to TRAIL concentrations using the calibration curves. The minimum detectable dose was $64 \mathrm{pg} / \mathrm{ml}$. Intra-assay and interassay variation was $5.5-7.4 \%$ and $3.8-8.0 \%$, respectively. The ELISA was found to be specific for TRAIL; cross reactivity with TNF $\alpha$ was absent and the signal could be blocked specifically by the addition of soluble TRAIL receptors.

\section{Statistical analysis}

Data are presented as mean (SEM). Differences in mean sTRAIL levels between the patient groups and normal controls were determined by ANOVA and Bonferroni post hoc test (Gaussian distribution) and by the $\chi^{2}$ test. The

Table 1 Characteristics of patients with systemic lupus erythematosus

\begin{tabular}{|c|c|c|c|}
\hline Variable & Active $(n=20)$ & Inactive $(n=20)$ & p Value \\
\hline Age (years) (mean (range)) & 40.3 (19 to 77 ) & 41.0 (23 to 72$)$ & $>0.05$ \\
\hline Male/female & $4 / 16$ & $3 / 17$ & \\
\hline Anti-dsDNA by Farr (IU/ml) & $162.6(57.6)$ & $15.35(3.4)$ & 0.015 \\
\hline $\mathrm{C} 3(\mathrm{~g} / \mathrm{l})$ & $0.757(0.080)$ & $0.982(0.060)$ & 0.032 \\
\hline $\mathrm{C} 4$ (g/l) & $0.105(0.010)$ & $0.148(0.010)$ & 0.047 \\
\hline SLEDAI & $9.950(1.065)$ & $1.950(0.387)$ & $<0.0001$ \\
\hline CRP (mg/l) & $35.45(10.68)$ & $3.45(1.06)$ & 0.0005 \\
\hline Creatinine $(\mu \mathrm{mol} / \mathrm{l})$ & $91.60(8.54)$ & $96.00(7.54)$ & 0.70 \\
\hline Leucocytes $\left(\times 10^{9} / \mathrm{I}\right)$ & $4.42(0.50)$ & $5.40(0.50)$ & 0.15 \\
\hline Neutrophils $\left(\times 10^{9} / \mathrm{I}\right)$ & $3.24(0.58)$ & $3.78(0.41)$ & 0.44 \\
\hline Monocytes $\left(\times 10^{9} / \mathrm{l}\right)$ & $0.28(0.05)$ & $0.45(0.05)$ & 0.016 \\
\hline Lymphocytes $\left(\times 10^{9} / \mathrm{I}\right)$ & $0.81(0.14)$ & $1.04(0.16)$ & 0.29 \\
\hline sTRAIL $(\mathrm{pg} / \mathrm{ml})$ & $861.8(138.7)$ & $1010.0(168.0)$ & 0.50 \\
\hline Renal disease & 6 & - & \\
\hline Central nervous system disease & 3 & - & \\
\hline Serositis & 4 & - & \\
\hline Haematological disease & 7 & - & \\
\hline Polyarthritis & 6 & - & \\
\hline Skin involvement & 4 & - & \\
\hline Fever & 5 & - & \\
\hline No immunosuppressive drugs & 11 & 6 & \\
\hline Prednisolone $(2.5$ to $10 \mathrm{mg})$ & 3 & 8 & \\
\hline Azathioprine (50 to $150 \mathrm{mg}$ ) & - & 1 & \\
\hline Prednisolone + azathioprine & 6 & 5 & \\
\hline
\end{tabular}

Values are mean (SEM) or $n$, unless stated.

Significant $p$ values in bold. 


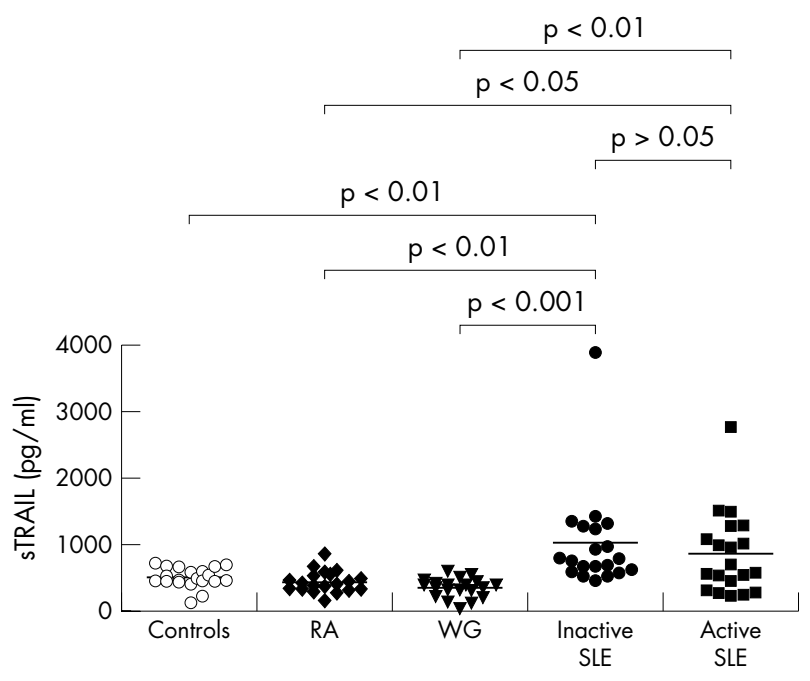

Figure 1 Serum soluble TNF related apoptosis inducing ligand (sTRAIL) concentrations $(\mathrm{pg} / \mathrm{ml})$ in SLE patients with inactive disease $(\mathrm{n}=20)$, SLE patients with active disease $(n=20)$, disease control patients with rheumatoid arthritis $(n=20)$, disease control patients with Wegener's granulomatosis $(n=20)$, and healthy controls $(n=20)$. The horizontal lines give the mean sTRAIL value.

Spearman test was used to determine correlations. Student's $t$ test was used to determine differences between sTRAIL levels in men and women (control group). A probability $(p)$ value of $<0.05$ was considered significant.

\section{RESULTS}

Characteristics of the SLE patients are given in table 1. Patients with rheumatoid arthritis had a mean (SEM) C reactive protein concentration of $10.5(2.1) \mathrm{mg} / \mathrm{l}$, a mean serum creatinine of 79.9 (2.5) $\mu \mathrm{mol} / \mathrm{l}$, and a mean leucocyte count of $6.9(0.3) \times 10^{9} / 1$. Patients with Wegener's granulomatosis had a mean $C$ reactive protein concentration of 7.3 (1.7) $\mathrm{mg} / \mathrm{l}$, a mean serum creatinine of 109.5 (7.9) $\mu \mathrm{mol} / \mathrm{l}$, and a mean leucocyte count of $7.8(0.9) \times 10^{9} / 1$.

To evaluate whether sTRAIL levels are influenced by sex or age, or both, we determined the correlation between sTRAIL level and age, and we analysed the difference in sTRAIL values between men and women in the control group. There was no difference in mean sTRAIL concentration between men $(\mathrm{n}=9 ; 557.7(39.2) \mathrm{pg} / \mathrm{ml})$ and women $(\mathrm{n}=11 ; 469.9$ (50.8) $\mathrm{pg} / \mathrm{ml}) \quad(\mathrm{p}=0.2)$. There was also no correlation between age and sTRAIL concentration $(\mathrm{p}=0.31, r=-0.24)$.

The mean (SEM) serum STRAIL concentration was 1010.2 (168.0) $\mathrm{pg} / \mathrm{ml}$ for patients with inactive disease and 861.8 (138.7) $\mathrm{pg} / \mathrm{ml}$ for those with active disease. The difference between the two groups was not significant $(\mathrm{p}>0.05)$.

Eighty three per cent of the SLE patients ( 33 of 40 ) had a mean sTRAIL level above that of the healthy volunteers, at 509 (33.8) pg/ml. Of the 20 patients with inactive disease one had a serum level below the mean control value. In patients with active disease this was seen in six of the 20 patients $\left(\mathrm{p}=0.037, \chi^{2}\right.$ test $)$.

The serum sTRAIL concentration in the whole group of SLE patients was 936.0 (108.2) pg/ml. Values were 443.8 (36.1) $\mathrm{pg} / \mathrm{ml}$ in patients with rheumatoid arthritis and 357.1 (32.2) $\mathrm{pg} / \mathrm{ml}$ in those with Wegener's granulomatosis. Serum sTRAIL concentrations in SLE patients were higher than those in healthy volunteers or disease control patients with rheumatoid arthritis or Wegener's granulomatosis $(p<0.05$; fig 1). Serum sTRAIL concentrations in rheumatoid arthritis did not differ from those in the healthy volunteers or the patients with Wegener's granulomatosis $(p>0.05)$.

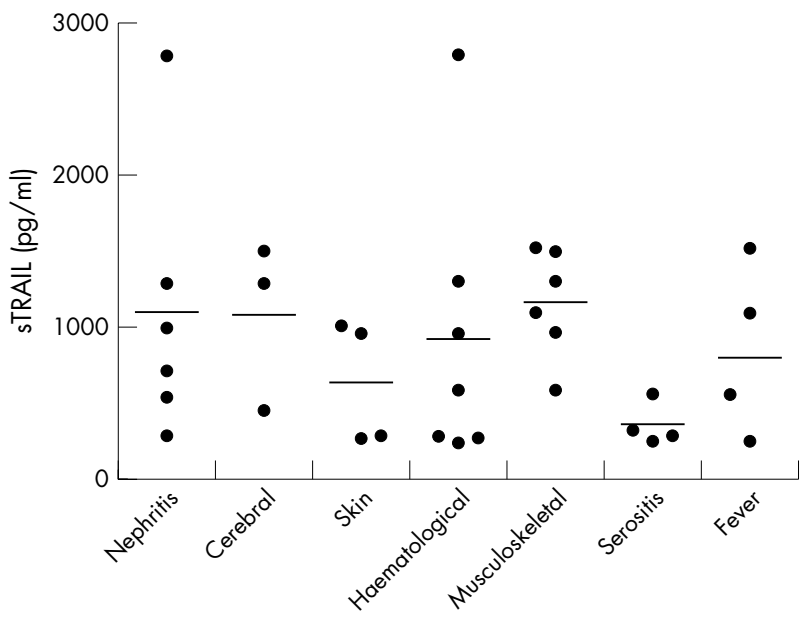

Figure 2 Serum soluble TNF related apoptosis inducing ligand (sTRAIL) concentrations $(\mathrm{pg} / \mathrm{ml})$ in patients with systemic lupus erythematosus (SLE) who had active disease $(n=20)$ divided by clinical disease manifestation $(n=35)$. One patient could have different manifestations of $\mathrm{SLE}$; thus 35 disease manifestations were found in 20 patients. The horizontal lines give the mean sTRAlL value.

Concentrations in Wegener's granulomatosis did not differ from those in the healthy volunteers $(\mathrm{p}>0.05)$.

We examined the association between the level of serum STRAIL and specific clinical features (fig 2). No clear relation was found between serum sTRAIL concentration and renal, cerebral, cutaneous, serosal, haematological, or musculoskeletal disease manifestations. Patients with serositis seemed to have lower serum sTRAIL levels, although numbers were small. Furthermore there was no correlation between the SLEDAI score and serological indices of disease activity such as anti-dsDNA and complement C4 levels, and no correlation with $C$ reactive protein levels. However, there was a positive correlation between serum sTRAIL level and complement C3 $(\mathrm{p}=0.02)$.

Leucopenia is seen in patients with active SLE. As sTRAIL can induce apoptosis in lymphocytes, monocytes, and neutrophils, we analysed whether sTRAIL levels were correlated with blood cell counts. Analysing all patients, no correlation was found between serum sTRAIL concentration and monocyte, lymphocyte, or leucocyte counts. However, when we focused on six patients with neutropenia $\left(<1.5 \times 10^{9}\right.$ neutrophils/l; three with active and three with inactive SLE) we found that the serum sTRAIL concentrations in these patients tended to be higher than in SLE patients without neutropenia, at 1455 (626) $v 853.6$ (66.7) pg/ $\mathrm{ml}(\mathrm{p}=0.057)$.

Finally, we examined the relation between sTRAIL concentrations and immunosuppressive drug treatment (prednisolone and azathioprine). No correlation between the use of these agents and sTRAIL values was found (data not shown).

\section{DISCUSSION}

Increased neutrophil, monocyte, and lymphocyte apoptosis is a characteristic feature of SLE pathophysiology. ${ }^{19}$ Thus the role of the apoptosis inducing ligands of the TNF family and their death receptors has been explored for years. The Fas/ FasL system contributes to increased apoptosis. The importance of the other death pathways is, however, uncertain. Recent interest had focused on TRAIL, several studies indicating that it is involved in the pathophysiology of autoimmune diseases including SLE. ${ }^{8-11}$ 
The present study showed higher sTRAIL concentrations in the serum of SLE patients compared with healthy volunteers and patients with rheumatoid arthritis or Wegener's granulomatosis. This suggests that increased serum sTRAIL levels are disease specific for SLE.

Through interaction with its death receptors TRAIL-Rl and TRAIL-R2, increased sTRAIL concentrations can stimulate increased apoptosis of lymphocytes and monocytes and may have a pathophysiological role in SLE, as increased apoptosis can result in the accumulation of apoptotic cells. Accumulation of apoptotic cells might induce autoimmunity. ${ }^{20}$

A question remains about the origin of the increased serum sTRAIL levels in SLE patients. Peripheral blood lymphocytes are activated in SLE patients even during clinically inactive disease. $^{21} \mathrm{~T}$ cell activation has been found to contribute to increased expression of TRAIL and other apoptotic ligands on lupus $\mathrm{T}$ cells isolated from SLE patients. ${ }^{10}$ In vitro, furthermore, TRAIL could be released from activated T cells ${ }^{22}$ as well as from stimulated monocytes. ${ }^{23}$ These findings are supported by increased gene expression of TRAIL and its decoy receptors in peripheral blood mononuclear cells (PBMC) from SLE patients. ${ }^{11}$ This overexpression could result in increased TRAIL concentrations.

Interferons (IFN $\alpha, \beta$, and $\gamma$ ) might also play an important role. Overexpression of IFN induced genes occurs in PBMC of paediatric SLE patients. ${ }^{24}$ This is of interest as human monocytes rapidly express TRAIL following activation with IFN $\alpha$ and IFN $\gamma .{ }^{25}{ }^{26}$ Furthermore in breast cancer cell lines, using DNA microarrays to profile TRAIL-mediated gene expression, interaction between TRAIL death signalling and IFN pathways (including interferon $\beta$ and $\gamma$ ) is suggested. ${ }^{27}$

Increased concentrations of sTRAIL may be explained by immunosuppressive drugs, which are known to induce apoptosis. This could subsequently lead to sTRAIL release from apoptotic cell fragments. For this reason we examined the relation between sTRAIL concentrations and the use of immunosuppressive drugs (prednisolone and azathioprine). We did not find a clear correlation in this small patient population, which excludes a substantial influence of drugs.

It was of interest that serum sTRAIL concentrations in patients with quiescent disease were more often increased than in patients with active disease. As TRAIL has an extremely short calculated half life of only 30 minutes $^{28}$ this indicates continuous TRAIL production or secretion. Furthermore, as $30 \%$ of the patients with active disease had a level below the mean serum STRAIL, we conclude that serum sTRAIL levels tend to decrease during, or perhaps prior to, active disease. This could be interpreted as binding of TRAIL to its receptors, distribution of sTRAIL throughout the body, or decreased TRAIL production. Binding of sTRAIL to its death receptors could lead to increased apoptosis of monocytes and lymphocytes. This is supported by the decreased monocyte and lymphocyte counts found in patients with active SLE (table 1). We were, however, unable to find a correlation between serum sTRAIL levels and blood cell counts in patients with SLE.

Recently Matsuyama et al ${ }^{13}$ showed that serum TRAIL values correlated negatively with neutrophil counts in SLE patients, suggesting that there is sTRAIL induced apoptosis of neutrophils in SLE. Our data are largely in accord with Matsuyama's data. Probably because of the small number of patients with neutropenia in our study (only six), the relation we found did not reach significance. The serum sTRAIL values in the patients with neutropenia, however, tended to be higher than in the patients without neutropenia $(\mathrm{p}=0.057)$.

The correlation between sTRAIL level and complement C3 is unexpected and unexplained. We cannot exclude the possibility that correlations were not demonstrated owing to the relatively small number of patients with a very heterogeneous disease.

Recently it was shown that TRAIL is important in the prevention of autoimmune diseases in experimental animal models. ${ }^{29-31}$ Blocking TRAIL with soluble TRAIL receptor exacerbated autoimmune encephalomyelitis ${ }^{29}$ and enhanced proliferation of autoreactive lymphocytes or synovial cells. ${ }^{30}$ Furthermore, TRAIL deficient C57BL/6 mice have an increased susceptibility to autoimmune diseases. ${ }^{31}$ Our results in SLE patients contrast with animal data but do not exclude an important function of sTRAIL in these patients. A prospective longitudinal study is needed to investigate serum STRAIL values over time with respect to disease activity and immunosuppressive treatment. Investigation of TRAIL and TRAIL-R expression and function in tissues, and on monocytes and lymphocytes, in SLE patients is also eagerly awaited.

\section{Conclusions}

In this study we report that increased serum sTRAIL concentrations in SLE patients seems to be disease specific. Levels in patients with inactive disease are more often increased than in patients with active disease. These findings could indicate an important role for sTRAIL in the pathogenesis of SLE. However, the exact mechanism and significance of this remain to be elucidated in larger prospective studies.

\section{Authors' affiliations}

M N Lub-de Hooge, Department of Hospital Pharmacy, University Hospital Groningen, Groningen, Netherlands

E G E de Vries, S de Jong, Medical Oncology, University Hospital Groningen

M Bïl, Clinical Immunology, University Hospital Groningen

\section{REFERENCES}

1 White S, Rosen A. Apoptosis in systemic lupus erythematosus. Curr Opin Rheumatol 2003;5:557-62.

2 Nagata S. Fas ligand-induced apoptosis. Annu Rev Genet 1999;33:29-55.

3 Famularo G, Nucera E, Marcellini S, De Simone C. Fas/Fas ligand on the road: an apoptotic pathway common to AIDS, autoimmunity, lymphoproliferation and transplantation. Med Hypotheses 1999;53:50-62.

4 Cheng J, Zhou T, Liu C, Shapiro JP, Brauer MJ, Kiefer MC, et al. Protection from Fas-mediated apoptosis by a soluble form of the Fas molecule. Science 1994;263:1759-62.

5 Nozawa K, Kayagaki N, Tokano Y, Yagita H, Okumura K, Hasimoto H. Soluble Fas (APO-1, CD95) and soluble Fas ligand in rheumatic diseases. Arthritis Rheum 1997:40:1126-9.

6 Wiley SR, Schooley K, Smolak PJ, Din WS, Huang CP, Nicholl JK, et al. Identification and characterization of a new member of the TNF family that induces apoptosis. Immunity 1995;3:673-82.

7 LeBlanc HN, Ashkenazi A. Apo2L/TRAIL and its death and decoy receptors. Cell Death Differ 2003;10:66-75.

8 Huang WX, Huang P, Gomes A, Hillert J. Apoptosis mediators FasL and TRAIL are upregulated in peripheral blood mononuclear cells in MS. Neurology, 2000;55:928-34

9 Matsumura R, Umemiya K, Kagami M, Tomioka H, Tanabe E, Sugiyama T, et al. Expression of TNF-related apoptosis inducing ligand (TRAIL) on infiltrating cells and of TRAIL receptors on salivary glands in patients with Sjogren's syndrome. Clin Exp Rheumatol 2002;20:791-8.

10 Kaplan MJ, Lewis EE, Shelden EA, Somers E, Pavlic R, McCune WJ, et al. The apoptotic ligands TRAIL, TWEAK, and Fas ligand mediate monocyte death induced by autologous lupus T cells. J Immunol 2002; 169:6020-9.

11 Rus V, Atamas SP, Shustova V, Luzina IG, Selaru F, Magder LS, et al. Expression of cytokine- and chemokine-related genes in peripheral blood mononuclear cells from lupus patients by cDNA array. Clin Immunol 2002;102:283-90.

12 Bïl M, Horst G, Limburg PC, Kallenberg CG. Anti-CD3-induced and anti-Fasinduced apoptosis in systemic lupus erythematosus (SLE). Clin Exp Immunol 2001;123:127-32.

13 Matsuyama W, Yamamoto M, Higashimoto I, Oonakahara KI, Watanabe M, Machida K, et al. TNF related apoptosis inducing ligand is involved in neutropenia of systemic lupus erythematosus. Blood 2004;104:184-91 Epub 2004 Mar 04.

14 Tan EM, Cohen AS, Fries JF, Masi AT, McShane DJ, Rothfield NF, et al. The 1982 revised criteria for the classification of systemic lupus erythematosus. Arthritis Rheum 1982;25:1271-7.

15 Bombardier C, Gladman DD, Urowitz MB, Caron D, Chang CH. Derivation of the SLEDAI. A disease activity index for lupus patients. The Committee on Prognosis Studies in SLE. Arthritis Rheum 1992;35:630-40. 
16 Bijl M, Horst G, Limburg PC, Kallenberg CG. Fas expression on peripheral blood lymphocytes in systemic lupus erythematosus (SLE): relation to lymphocyte activation and disease activity. Lupus 2001;10:866-72.

17 Arnett FC, Edworthy SM, Bloch DA, McShane DJ, Fries JF, Cooper NS, et al. The American Rheumatism Association 1987 revised criteria for the classification of rheumatoid arthritis. Arthritis Rheum 1988;31:315-24.

18 Leavitt RY, Fauci AS, Bloch DA, Michel BA, Hunder GG, Arend WP, et al. The American College of Rheumatology 1990 criteria for the classification of Wegener's granulomatosis. Arthritis Rheum 1990;33:1101-7.

19 Ren Y, Tang J, Mok MY, Chan AW, Wu A, Lau CS. Increased apoptotic neutrophils and macrophages and impaired macrophage phagocytic clearance of apoptotic neutrophils in systemic lupus erythematosus. Arthritis Rheum 2003:48:2888-97.

20 Mevorach D, Zhou JL, Song X, Elkon KB. Systemic exposure to irradiated apoptotic cells induces autoantibody production. J Exp Med 1998;188:387-92.

21 Spronk PE, Horst G, Van Der Gun BT, Limburg PC, Kallenberg CG. AntidsDNA production coincides with concurrent $B$ and $T$ cell activation during development of active disease in systemic lupus erythematosus (SLE). Clin Exp Immunol 1996;104:446-53.

22 Monleon I, Martinez-Lorenzo MJ, Monteagudo L, Lasierra P, Taules M, Iturralde $M$, et al. Differential secretion of Fas ligand- or APO2 ligand'TNFrelated apoptosis-inducing ligand-carrying microvesicles during activationinduced death of human T cells. J Immunol 2001;167:6736-44.

23 Halaas O, Vik R, Ashkenazi A, Espevik T. Lipopolysaccharide induces expression of APO2 ligand/TRAIL in human monocytes and macrophages. Scand J Immunol 2000:51:244-50.
24 Bennett L, Palucka AK, Arce E, Cantrell V, Borvak J, Banchereau J, et al. Interferon and granulopoiesis signatures in systemic lupus erythematosus blood. J Exp Med 2003;197:711-23.

25 Griffith TS, Wiley SR, Kubin MZ, Sedger LM, Maliszewski CR, Fanger NA Monocyte-mediated tumoricidal activity via the tumor necrosis factor-related cytokine, TRAIL. J Exp Med 1999; 189:1343-54.

26 Tecchio C, Huber V, Scapini P, Calzetti F, Margotto D, Todeschini G, et al. IFN $\alpha$-stimulated neutrophils and monocytes release a soluble form of TNFrelated apoptosis-inducing ligand (TRAIL/Apo-2 ligand) displaying apoptotic activity on leukemic cells. Blood, 2004;15 [Epub ahead of print].

27 Kumar-Sinha C, Varambally S, Sreekumar A, Chinnaiyan AM. Molecular cross-talk between the TRAIL and interferon signaling pathways. J Biol Chem 2002;277:575-85

28 Kelley SK, Harris LA, Xie D, Deforge L, Totpal K, Bussiere J, et al. Preclinical studies to predict the disposition of Apo2L/tumor necrosis factor-related apoptosis-inducing ligand in humans: characterization of in vivo efficacy, pharmacokinetics, and safety. J Pharmacol Exp Ther 2001;299:31-8.

29 Hilliard B, Wilmen A, Seidel C, Liu TS, Goke R, Chen Y. Roles of TNF-related apoptosis-inducing ligand in experimental autoimmune encephalomyelitis. J Immunol 2001;166:1314-19.

30 Song K, Chen Y, Goke R, Wilmen A, Seidel C, Goke A, et al. Tumor necrosis factor-related apoptosis-inducing ligand (TRAIL) is an inhibitor of autoimmune inflammation and cell cycle progression. J Exp Med 2000;191:1095-104.

31 Lamhamedi-Cherradi SE, Zheng SJ, Maguschak KA, Peschon J, Chen YH. Defective thymocyte apoptosis and accelerated autoimmune diseases in TRAIL - / - mice. Nat Immunol 2003;4:255-60. 